\title{
Physician Factors Associated with Polypharmacy and Potentially Inappropriate Medication Use
}

\author{
Kenya Ie, MD, PhD, MPH, Maria Felton, PharmD, BCPS, \\ Sydney Springer, PharmD, BCPS, Stephen A. Wilson, MD, MPH, \\ and Steven M. Albert, PhD
}

Background: Despite accumulating evidence about the harm of polypharmacy in family medicine, few studies have investigated factors related to polypharmacy. The objective of this study was to explore factors related to physicians' prescribing behavior.

Methods: We conducted a survey of physicians at 5 family medicine residency practices and a linked health record review of their patients $\geq 65$ years old. The determinants of physicians' mean number of prescriptions and potentially inappropriate medications (PIMs) were examined using a generalized linear model.

Results: A total of 61 physicians (38 residents, 23 fellows/faculty) completed the survey, and 2103 visits by 932 patients seen by these physicians were analyzed. The mean numbers of prescriptions and PIMs per visit per physician were 9.50 and 0.46 , respectively. After controlling for patient race and age, low prescribers were more likely to consider the number of medications $(P=.007)$ and benefit/risk information for deprescribing $(P=.017)$ when making prescribing decisions. Use of the Beers List was marginally significant in lower PIM prescribing $(P=.05)$. Physicians' sex, duration of experience, and perceived confidence were not associated with prescribing patterns.

Conclusions: Conscious consideration concerning the number of medications and benefit/risk information, as well as using the Beers List, were associated with less polypharmacy and fewer PIMs. (J Am Board Fam Med 2017;30:528-536.)

Keywords: Deprescribing, Linear Models, Physicians, Polypharmacy, Potentially Inappropriate Medication List, Risk Assessment, Surveys and Questionnaires

Polypharmacy is the use of more drugs than are clinically indicated, ${ }^{1,2}$ or, more descriptively, the use of more than a certain number of drugs (eg, 25). ${ }^{1,3}$ Polypharmacy has become more common among the elderly ${ }^{4}$ and is related to several problems, including increased risk of being prescribed

This article was externally peer reviewed.

Submitted 10 March 2017; revised 22 March 2017; accepted 29 March 2017.

From the Department of Family Medicine, University of Pittsburgh, Pittsburgh (KI, MF, SS, SAW); University of Pittsburgh Graduate School of Public Health, Pittsburgh (KI, SMA); and UPMC St. Margaret, Pittsburgh, PA (MF, SS, SAW).

Funding: This study was funded by the Japan Primary Care Association (grant 28-02-003).

Prior presentation: Poster presented at the 44th North American Primary Care Research Group Annual Meeting, Colorado Springs, Colorado, November 2016.

Conflict of interest: none declared.

Corresponding author: Kenya Ie, MD, PhD, MPH, 130 De Soto Street, Pittsburgh, PA 15261(E-mail: iekenya0321@gmail.com). potentially inappropriate medications (PIMs), ${ }^{5}$ which are delineated in several drug lists, such as the American Geriatrics Society Beers criteria. ${ }^{6}$ Both polypharmacy and PIMs increase adverse drug events, worsen physical function, and result in excess health care utilization. ${ }^{5-7}$ In $2014,20 \%$ of total National Health Expenditures were spent for Medicare, and nearly half of the Medicare expenditure involved prescription drug-related costs. ${ }^{8}$ Medication misuse and polypharmacy cost the United States more than $\$ 177$ billion every year. ${ }^{9}$

Family physicians need to be aware of these medication-related problems within their own practices, as geriatric care in family medicine practices (FMPs) is likely to become more prevalent and important with increasingly aged populations. ${ }^{10}$ The first published data of PIM prevalence in the United States indicated PIM use by approximately $23 \%$ of patients $\geq 65$ years of age who 
visited clinics at least twice over a 2-year period. ${ }^{11}$ Polypharmacy prevalence in primary care in several countries has been reported. ${ }^{12,13}$ To our knowledge, however, no report has been published with a focus on polypharmacy in US FMPs. Based on unpublished internal quality data of older adults who visited FMPs more than once a year and had $\geq 2$ chronic conditions, $86.1 \%$ were prescribed $\geq 5$ medications and $33.4 \%$ were prescribed $\geq 1$ PIM. Among patients who met polypharmacy or PIM criteria, less than half experienced a reduction in the amount of prescription medications or PIMs during a year. Thus, polypharmacy and PIMs are important problems that should be addressed in family medicine.

Deprescribing refers to the process of tapering, stopping, discontinuing, or withdrawing drugs, with a goal of managing polypharmacy and improving outcomes. ${ }^{14}$ Deprescribing with a focus on certain types of PIMs (eg, nonsteroidal anti-inflammatory drugs, benzodiazepines) has been shown to improve patient outcomes ${ }^{15}$ and can be done safely. ${ }^{16}$ However, evidence is inconclusive about the effect of deprescribing that focuses on reducing the number of overall medications. A 2014 Cochrane review found inconsistent results among deprescribing studies that used either the Beers List, a pharmacist-led approach, or a multidisciplinary deprescribing intervention. ${ }^{17}$

In addition to the lack of evidence, deprescribing entails many practical challenges. Qualitative studies found that physicians tend to avoid discussing deprescribing with their elderly patients. ${ }^{18,19}$ Some reasons they highlighted were "preventive medication is not easy to reduce,"18,19 "lack of benefit/risk information of deprescribing,"18,19 "guideline pressure," 18 "medications initiated by specialists," 19 and "patients may feel it is a sign of giving up."18 Furthermore, the appropriateness of prescribed medications is multifactorial in most cases. Previously known factors associated with physicians' attitudes toward deprescribing include patient age, life expectancy, functional and cognitive status, comorbidity, expected medication adherence, insurance coverage, budgetary concerns, and the wishes of the patient and family. ${ }^{20}$ However, these studies did not address the association between potential factors and actual prescription behaviors.

The objectives of this study were to investigate variability in prescription patterns for multimorbid elderly patients across family physicians and to ex- plore factors related to prescription pattern variation, with the goal of informing interventions to reduce potentially harmful prescription.

\section{Methods}

We conducted a physician survey and a linked health record review of their patients aged $\geq 65$ years who visited 5 residency-affiliated FMPs. The study protocol was approved by the University of Pittsburgh Institutional Review Board (PRO15120091).

\section{Physician Survey}

From June to July 2016, family medicine residents, fellows, and faculty seeing patients at 1 of the 5 University of Pittsburgh Medical Center-affiliated FMPs were asked to respond to a survey and for permission to review patient records. Those who gave written consent for participation and electronic health record review, and had at least 1 active patient note for patients aged $\geq 65$ years during October 1, 2015, to June 6, 2016, were included in the final analyses.

Survey items were selected based on a literature review ${ }^{18-20}$ and a consultation process among researchers (2 family physicians and 2 clinical pharmacists who specialize in geriatric medicine). The preliminary questionnaire underwent several pilot tests, and the items were revised as appropriate. We evaluated physician demographics, their perceptions of the importance of and their confidence in deprescribing, their perceptions of the importance of deprescribing triggers and barriers, ${ }^{18-20}$ and the use of the Beers List ${ }^{6}$ and STOPP criteria. ${ }^{21}$ Level of deprescribing importance/confidence and the importance of triggers/barriers were assessed using 5 -point Likert-type scales ranging from 1 (not at all) to 5 (very much) for importance/confidence and 1 (not important) to 5 (very important) for triggers/ barriers (see the Appendix).

\section{Health Record Review}

Electronic health records of patients who were $\geq 65$ years old and who visited $\geq 1$ of 5 FMPs at least once from October 2015 to June 2016 were extracted from a reporting database by a systems analyst who also served as an honest broker. We extracted data on patient age, sex, race, and the 6 most prevalent comorbidities $(>30 \%)$ in our practices (hypertension, hyperlipidemia, osteoarthritis, 
gastroesophageal reflux, diabetes mellitus, and depression). We counted the total number of both prescription medication and PIM orders at each visit. The list of PIMs in this study were defined based on medications recommended to "avoid," as listed in 2015 American Geriatrics Society Beers Criteria for Potentially Inappropriate Medication Use in Older Adults ${ }^{6}$ (Table 1).

\section{Statistical Analyses}

To test the representativeness of FMP patients included in the final analysis, we first stratified patients into 2 groups: those seen by participating physicians and those seen by nonparticipating physicians. We used only the aggregate patient data of nonparticipating physicians as a means to compare characteristics between participating doctors' and nonparticipating doctors' patient panels. For the main analyses, the mean numbers of prescription medications and PIM orders per visit per physician were calculated as the main response variables. These response variables were treated as continuous variables. Physicians' age, years since graduation, and responses to the 5-point Likert-type scales were treated as continuous variables, assuming that they have the same interval properties. Physicians' sex, board certification status, and use of the Beers List and STOPP criteria were treated as binary, and practicing sites was treated as nominal. Univariable and multivariable regressions were used to determine the association of each variable with the mean prescription numbers and mean PIM orders per visit per physician. In addition, the proportion of minority patients and the age distribution of patients seen by the physicians were used as covariates. In this exploratory analysis, we sought a minimum of 50 physician responses to allow multivariable linear regression with approximately 5 explanatory variables in our model. We used a significance level of 0.05 for hypothesis testing. The adjusted $R^{2}$ statistic and the Akaike information criterion were used where appropriate for model selection. Multicollinearity was tested based on the variance inflation factor, with a cutoff at 10. Statistical analyses were performed using STATA/SE 14.2 (StataCorp, College Station, TX).

\section{Results}

Of the 117 family physicians invited to participate and who had at least 1 active patient note at the 5
Table 1. Characteristics of Patients $(n=932)$ and Visits $(\mathrm{n}=2,103)$ Seen by 61 Participating Physicians

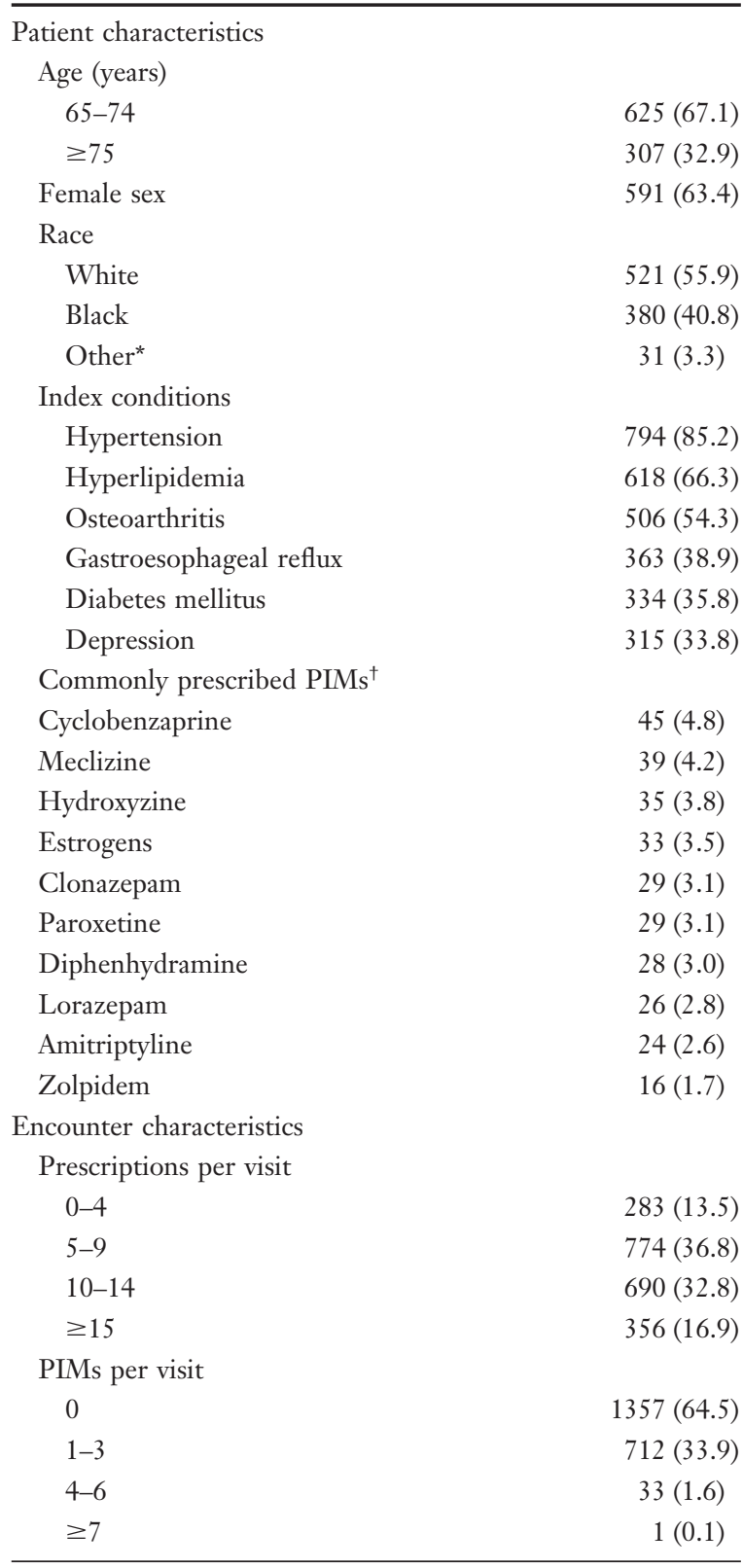

Data are number (\%) of patients or visits.

* "Other" includes Asian and others.

${ }^{\dagger}$ Potentially inappropriate medications (PIMs) were defined based on the table 2 of 2015 American Geriatrics Society Beers Criteria for Potentially Inappropriate Medication Use in Older Adults. $^{6}$

FMPs during the period October 1, 2015, to June 6, 2016, 61 completed the survey and agreed to a review of patient data-a $52 \%$ response rate; 38 were residents, 23 were fellows/faculty. Among 4810 clinic visits by 1900 patients, 2103 visits (43.7\%) by 932 patients (49.1\%) were seen by these participating physicians. Table 1 reveals the char- 
Table 2. Physician Survey Responses $(n=61)$

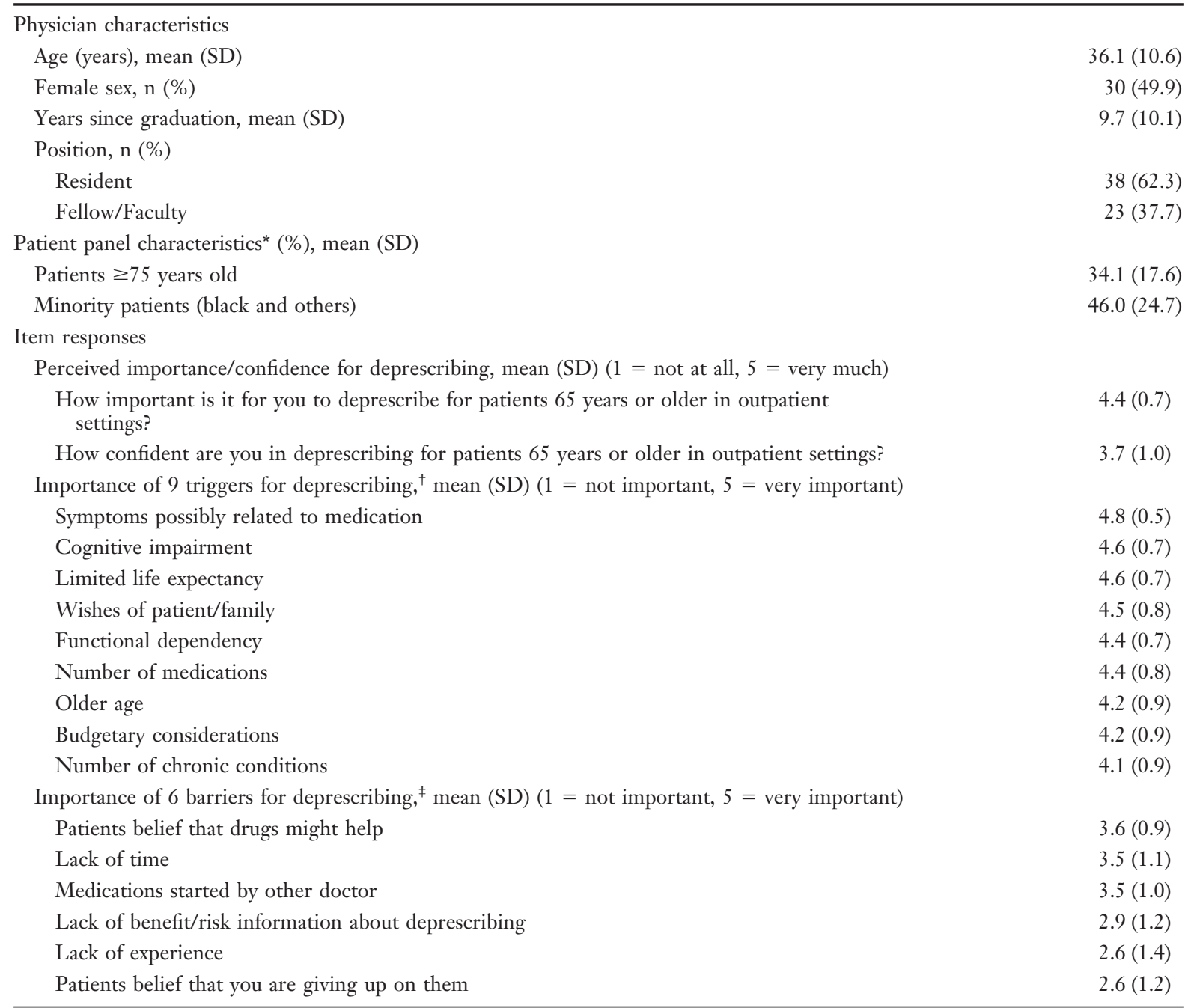

*Data obtained from health record review.

t"How important are the following factors for you to consider deprescribing?"

‡"To what extent do the following factors make you less likely to deprescribe?"

acteristics of patients seen by participating physicians and of their visits. The characteristics were similar between patients seen by participating physicians and those seen by nonparticipating physicians in terms of patient demographics, comorbidities, and prescription patterns. On average, approximately one third of elderly patients were aged $\geq 75$ years. The patients $\geq 65$ years old participating in our study included a higher proportion of racial minorities (black and others, $46.0 \%$ ) than the general US population (nonwhite, 22.9\%). ${ }^{22}$ The prevalence of polypharmacy ( $\geq 5$ medications) and PIM use among elderly patients treated by participating physicians were $86.5 \%$ and $35.5 \%$, respectively. These prevalences are consistent with our previous data (unpublished) despite the different time frame and the transition of coding system (International Classification of Diseases, Ninth Revision, Clinical Modification in the previous data and International Classification of Diseases, Tenth Revision in this study). Among the PIMs, the most common 3 and their per-visit frequencies were cyclobenzaprine, $4.8 \%$; meclizine, $4.2 \%$; and hydroxyzine, $3.8 \%$. The mean (standard deviation) of the total and PIM prescriptions per visit per physician were 9.50 (1.94) and $0.46(0.29)$, respectively.

Table 2 contains the physicians' responses to the survey. Of the 61 physicians included in our analyses, 38 were residents and 23 were fellow/faculty physicians, with an overall mean of 9.7 years since medical school graduation. Overall, participating 
Table 3. Multivariable Regression: Factors Associated with Physicians' Numbers of Prescriptions and Potentially Inappropriate Medication Orders

\begin{tabular}{lrr}
\hline Variables & Prescriptions & PIM Orders \\
\hline Lack of benefit/risk information about deprescribing* $^{*}$ & $-0.40(0.16)^{\dagger}$ & $-0.06(0.03)^{\dagger}$ \\
Number of medications* & $-0.67(0.24)^{\dagger}$ & $-0.07(0.04)$ \\
Proportion of minority patients & $-3.72(0.81)^{\dagger}$ & $-0.34(0.14)^{\dagger}$ \\
Proportion of patients aged $\geq 75$ & $-2.92(1.13)^{\dagger}$ & $-0.45(0.20)^{\dagger}$ \\
Use of the Beers List & & $-0.17(0.08)$ \\
Intercept & $16.31(1.32)^{\dagger}$ & $1.40(0.24)^{\dagger}$ \\
Adjusted $R^{2}$ (AIC) & $0.3939(228)$ & $0.2062(12.4)$ \\
\hline
\end{tabular}

Data are $\boldsymbol{\beta}$ (standard error). All variables included in the fitted models are reported in this table.

*The importance of triggers/barriers were assessed using 5-point Likert scales ranging from 1(Not important) to 5(very important). ${ }^{\dagger} P<.05$.

${ }^{\ddagger}$ Reference group includes those physicians who did not use the Beers List.

AIC, Akaike information criterion; PIM, potentially inappropriate medication.

physicians were highly aware of the importance of deprescribing in outpatient settings. However, the level of confidence was not at the same level as their perceived importance. Among the triggers for deprescribing, "symptoms possibly related to medication," "cognitive impairment," and "limited life expectancy" were ranked as more important than "number of medications," "[patient's] older age," "budgetary considerations," and "number of chronic conditions." As for barriers, participating physicians ranked "the beliefs of the patients that drugs might help," "lack of time," and "medications started by other doctor" higher than "lack of benefit/risk information about deprescribing," "lack of experience," and "the beliefs of the patients that you are giving up on them."

The multivariable regression model for the number of prescriptions and the model for the number of PIMs are displayed in Table 3. After controlling for patient race and age, physicians who prescribe less were significantly more likely to rank benefit/risk information of deprescribing $(P=$ $.017)$ and number of medications $(P=.007)$ as more important than those who prescribed more medications. Prescribing fewer PIMs was associated with greater emphasis on benefit/risk information about deprescribing $(P=.028)$ and number of medications $(P=.075)$, and greater use of the Beers List $(P=.05)$. There was no multicollinearity between independent variables included in both fitted models. Physicians' sex, duration of experience, and perceived confidence were not associated with the prescribing pattern.

\section{Discussion}

We found that physicians who ranked the number of medications and benefit/risk information regarding deprescribing as more important than their peers prescribed fewer medications and PIMs after controlling for patient race and age. The use of the Beers List was associated with less PIM prescribing but with borderline significance. Physicians' sex, duration of clinical experience, and perceived confidence levels had no effect on the numbers of prescriptions.

Our results, especially if replicated in other FMPs, suggest several potential implications for improving the quality of geriatric care in FMPs. First, the number of prescriptions would be an important clinical indicator for the quality of geriatric care in FMPs. A recent large cohort study of US Medicare beneficiaries found that the strongest predictor of PIM use among the factors studied was the number of drugs dispensed. ${ }^{23}$ Similarly, multiple studies have consistently revealed that taking more prescription medications increases the risk of exposure to a PIM. ${ }^{24,25}$ The number of prescription medications, as well as the number of PIMs themselves, could be a reasonable red flag that warrants deprescribing for older multimorbid patients in FMPs.

Second, physicians' emphasis on the benefit/risk information of deprescribing was found to be related to less prescriptions and PIMs per visit. A lack of evidence for the benefit/risk of deprescribing is known to be a common reason for prescribing $\mathrm{PIMs}^{26}$ or as a barrier to deprescribing. ${ }^{18,19}$ Medication optimization criteria, such as the Beers List, 
can be a resource for clinicians as a summary of the current best evidence regarding PIMs. Thus, increasing the use of the Beers List at FMPs could reduce the risk of PIM prescription by promoting evidence-based medication use in elderly patients.

Such medication optimization criteria can be fundamental for evidence-based medicine, which encompasses whole-person care. However, physicians sometimes use these evidence-based tools with a reductionist approach. For instance, a qualitative study found that physicians perceived drugoriented criteria as "not encompassing clinical judgment, or the quality of life, societal and familyrelated contexts of prescribing." ${ }^{19}$ According to Sackett et $\mathrm{al}^{27}$ however, evidence-based medicine is defined as "a systematic approach to clinical problem solving which allows the integration of the best available research evidence with clinical expertise and patient values." Thus, it may be worthwhile to remind clinicians that the adequate use of evidence-based tools can facilitate the whole-person approach, not be against it.

In addition to the physician-level factors, older patient age and a minority background had protective effects on the number of both prescriptions and PIMs, similar to previous studies. ${ }^{23,28-30}$ The lower medication exposure among these vulnerable populations could reflect a trade-off between polypharmacy and undertreatment. Multimorbidity has also been shown to be an independent trigger for potential prescribing omissions. ${ }^{25}$ Family physicians who treat multimorbid older adults at FMPs with a high proportion of racial minorities need to be aware of their potential bias toward both polypharmacy and undertreatment.

Our study had several limitations. First, our results may not be generalizable to US family medicine patients in general because the data were limited to family medicine residency programs where the majority of respondents were residents. It is possible that the prescribing patterns of residents are still being developed and that their attending physicians might have affected their prescribing behaviors. However, we confirmed that the results were similar between residents and fellows/faculty based on stratified analyses. Furthermore, the similar prevalence across 5 FMPs serving different socioeconomic groups suggests consistency across the health system. Second, the small sample size for the physician survey has limited statistical power, although our multivariable regression model re- vealed a satisfactory model fit. Finally, and most important, the appropriateness of the prescribed medications was not evaluated. For the future research, the appropriateness of prescribed medications, as well as the number of prescriptions as a risk factor, should be taken into consideration.

\section{Conclusion}

Polypharmacy and the use of PIMs were extremely common among patients $\geq 65$ years of age who visited FMPs. Physicians attuned to the number of medications and benefit/risk information prescribed fewer medications and PIMs after controlling for patient race and age. Our results warrant further research and education to address prescription-related problems among older patients in FMPs, with the goal of informing interventions to reduce potentially harmful prescriptions, asking, for example, how physician attunement (awareness, valuing, prioritization) can be increased.

The authors thank Drs. Vince Balestrino, Linda Hogan, and Patricia M. Klatt for their suggestions regarding the development of the questionnaire; the EPIC data development team and CARe for their support with data extraction; Dr. Jeanine M. Buchanich, Clair N. Smith, Sifang Zhao, and Shu Wang for their statistical assistance; and the Nippon Foundation for their support with this project.

To see this article online, please go to: http://jabfm.org/content/ 30/4/528.full.

\section{References}

1. Fulton MM, Allen ER. Polypharmacy in the elderly: a literature review. J Am Acad Nurse Pract 2005;17: 123-32.

2. Zarowitz BJ, Stebelsky LA, Muma BK, Romain TM, Peterson EL. Reduction of high-risk polypharmacy drug combinations in patients in a managed care setting Pharmacotherapy 2005;25:1636-45.

3. Viktil KK, Blix HS, Moger TA, Reikvam A. Polypharmacy as commonly defined is an indicator of limited value in the assessment of drug-related problems. Br J Clin Pharmacol 2007;63:187-95.

4. Charlesworth CJ, Smit E, Lee DS, Alramadhan F, Odden MC. Polypharmacy among adults aged 65 years and older in the united states: 1988-2010. J Gerontol A Biol Sci Med Sci. 2015;70: 989-95.

5. Goulding MR. Inappropriate medication prescribing for elderly ambulatory care patients. Arch Intern Med 2004;164:305-12.

6. American Geriatrics Society 2015 Beers Criteria Update Expert Panel. American Geriatrics Society 
2015 updated Beers criteria for potentially inappropriate medication use in older adults. J Am Geriatr Soc 2015;63:2227-46.

7. Gyllensten H, Rehnberg C, Jönsson AK, Petzold M, Carlsten A, Andersson Sundell K. Cost of illness of patient-reported adverse drug events: a populationbased cross-sectional survey. BMJ Open 2013;3: $1-12$.

8. NHE fact sheet. Baltimore: Centers for Medicare and Medicaid Services; 2015. Available from: https:// www.cms.gov/Research-Statistics-Data-and-Systems/ Statistics-Trends-and-Reports/NationalHealthExpendData/NHE-Fact-Sheet.html. Accessed June 7, 2017.

9. Veehof L, Stewart R, Haaijer-Ruskamp F, Jong BM. The development of polypharmacy. A longitudinal study. Fam Pract 2000;17:261-7.

10. Peterson L, Bazemore AW, Phillips RL Jr, et al. Family physicians' present and future role in caring for older patients. Am Fam Physician 2009;80:1072.

11. Buck MD, Atreja A, Brunker CP, et al. Potentially inappropriate medication prescribing in outpatient practices: prevalence and patient characteristics based on electronic health records. Am J Geriatr Pharmacother 2009;7:84-92.

12. Payne RA, Avery AJ, Duerden M, Saunders CL, Simpson CR, Abel GA. Prevalence of polypharmacy in a Scottish primary care population. Eur J Clin Pharmacol 2014;70:575-81.

13. Junius-Walker U, Theile G, Hummers-Pradier E. Prevalence and predictors of polypharmacy among older primary care patients in Germany. Fam Pract 2007;24:14-9.

14. Thompson W, Farrell B. Deprescribing: what is it and what does the evidence tell us? Can J Hosp Pharm 2013;66:201-2.

15. Reeve E, Shakib S, Hendrix I, Roberts MS, Wiese MD. The benefits and harms of deprescribing. Med J Aust 2014;201:9-12.

16. Iyer S, Naganathan V, McLachlan AJ, Le Couteur DG. Medication withdrawal trials in people aged 65 years and older: a systematic review. Drugs Aging 2008;25:1021-31.

17. Patterson S, Cadogan C, Kerse N, et al. Interventions to improve the appropriate use of polypharmacy for older people. Cochrane Database Syst Rev 2014;(10):CD008165.

18. Schuling J, Gebben H, Veehof LJG, HaaijerRuskamp FM. Deprescribing medication in very elderly patients with multimorbidity: the view of Dutch GPs. A qualitative study. BMC Fam Pract 2012;13:56.
19. Magin P, Goode S, Pond D. GPs, medications and older people: a qualitative study of general practitioners' approaches to potentially inappropriate medications in older people. Australas J Ageing 2014;34: e134-9.

20. Ní Chróinín D, Ní Chróinín C, Beveridge A. Factors influencing deprescribing habits among geriatricians. Age Ageing 2015;44:704-8.

21. O'Mahony D, O'Sullivan D, Byrne S, O'Connor MN, Ryan C, Gallagher P. STOPP/START criteria for potentially inappropriate prescribing in older people: version 2. Age Ageing 2015;44:213-8.

22. QuickFacts: United States. Washington, DC: US Census Bureau; 2015. Available from: https://www. census.gov/quickfacts/table/PST045215/00. Accessed November 22, 2016.

23. Jirón M, Pate V, Hanson LC, Lund JL, Jonsson Funk M, Stürmer T. Trends in prevalence and determinants of potentially inappropriate prescribing in the united states: 2007 to 2012. J Am Geriatr Soc 2016;64:788-97.

24. Alhmoud E, Khalifa S, Bahi AA. Prevalence and predictors of potentially inappropriate medications among home care elderly patients in Qatar. Int J Clin Pharm 2015;37:815-21.

25. San-José A, Agustí A, Vidal X, et al. Inappropriate prescribing to the oldest old patients admitted to hospital: prevalence, most frequently used medicines, and associated factors. BMC Geriatr 2015; $15: 42$.

26. Voigt K, Gottschall M, Köberlein-Neu J, et al. Why do family doctors prescribe potentially inappropriate medication to elderly patients? BMC Fam Pract 2016;17:93

27. Sackett DL, Rosenberg WC, Gray JA, Haynes RB, Richardson WS. Evidence based medicine: what it is and what it isn't. BMJ 1996;312:71-2.

28. Smedley BD, Stith AY, Nelson AR, eds; Institute of Medicine (US) Committee on Understanding and Eliminating Racial and Ethnic Disparities in Health Care. Unequal treatment: confronting racial and ethnic disparities in health care. Washington DC: National Academies Press; 2003.

29. Duran-Tauleria E, Rona RJ, Chinn S, Burney P. Influence of ethnic group on asthma treatment in children in 1990-1: national cross sectional study. BMJ 1996;313:148-52.

30. Ryall AH, Abdulah DR, Rios D, Wei JY, Hausdorff JM. Undertreatment of cardiovascular disease in ethnically diverse older adults: who should receive an electrocardiogram? J Am Geriatr Soc 2001;49: 1573-4. 
1. The following questions ask you to describe your educational/work experience. Please put a tick $\square$ in the box next to the answer of your choice or write in the space. Please select only one answer, unless otherwise specified.

- Age

- Sex $\square$ Female $\square$ Male

- Years since graduation (e.g. PGY $2 \rightarrow 2$ )

- Position

$\square$ Intern $\square$ Resident $\square$ Fellow $\square$ Faculty $\square$ Other (

- What percentage of your patients are 65 years or older? $\square 0-20 \% \quad \square 21-40 \% \quad \square 41-60 \% \quad \square 61-80 \% \quad \square 81-100 \%$

- Board certification status (all that apply)

$\square$ None $\square$ Family Medicine $\square$ Internal Medicine $\square$ Geriatric Medicine $\square$ Others (

- Geriatric training experience

$\square$ None $\square$ Geriatric Fellowship $\square$ Others (

2. Deprescribing refers to the process of tapering, stopping, discontinuing, or withdrawing drugs, with the goal of managing polypharmacy and improving outcomes.

Please select only one box next to the answer of your choice.

- In the past 3 months, how many times have you discussed deprescribing with patients 65 years or older in outpatient settings?

$\square$ None $\square 1 \sim 2$ times $\square 3 \sim 4$ times $\square$ more than 5 times

- In the past 3 months, how many times have you actually deprescribed for patients 65 years or older in outpatient settings?

$\square$ None $\square 1 \sim 2$ times $\square 3 \sim 4$ times $\square$ more than 5 times

- In general, how important is it for you to deprescribe for patients 65 years or older in outpatient settings?

$\square$ Not at all $\square$ Slightly $\square$ Somewhat $\square$ Moderately $\square$ Very much

- In general, how confident are you in deprescribing for patients 65 years or older in outpatient settings?

$\square$ Not at all $\square$ Slightly $\square$ Somewhat $\square$ Moderately $\square$ Very much

3. The following questions ask you to describe factors affecting your deprescribing decision. Please select all that apply.

- Which of the following factors make you more likely to deprescribe? (Please select all that apply)
$\square$ Older age $(\geq 65)$
$\square$ Older age $(\geq 75)$
$\square$ Number of prescription medication $(\geq 5)$
$\square$ Number of prescription medication $(\geq 10)$
$\square \geq 2$ chronic conditions
$\square \geq 5$ chronic conditions
$\square$ After hospital admission
$\square$ Acute symptom possibly related to medication

$\square$ Existence of potentially inappropriate medication listed in Beers criteria 
- Which of the following factors make you less likely to deprescribe? (Please select all that apply)
$\square$ Lack of time
$\square$ Lack of deprescribing experience
$\square$ Lack of benefit/risk information about deprescribing
$\square$ Patients belief that drugs might help
$\square$ Medications started by other doctor(s)

- Do you use any of specific criterias listed below to guide deprescribing? (Please select all that apply)
$\square$ No
$\square$ AGS-Beers criteria
$\checkmark$ STOPP/START criteria
$\square$ Others

Thank you for taking time out to participate in our survey.

We truly value the information you have provided. 